\title{
An Approach to Obligatory Secondary Education Teachers' Perception Regarding Orientation Processes and Response to Diversity
}

\author{
Milagros De la Rosa Hormiga', David Pérez-Jorge'2, \\ Candelaria de la Merced Díaz-González ${ }^{3}$, María del Carmen Rodríguez Jiménez², \\ María Sandra Marrero Morales 4 \\ ${ }^{1}$ Nursing Department, Universidad de La Laguna (ULL), San Cristobal de La Laguna, Spain \\ ${ }^{2}$ Faculty of Education, Universidad de La Laguna (ULL), San Cristobal de La Laguna, Spain \\ ${ }^{3}$ Nurse in Hospital Insular de Gran Canaria, Las Palmas, Spain \\ ${ }^{4}$ Faculty of Health Sciences, Universidad de Las Palmas de Gran Canaria (ULPGC), Las Palmas, Spain \\ Email: mhormiga@ull.es, dpjorge@ull.es, cdiazg@denf.ulpgc.es, mcrojime@ull.edu.es, \\ sandra.marrero@ulpgc.es
}

Received 14 February 2015; accepted 13 April 2015; published 16 April 2015

Copyright (C) 2015 by authors and Scientific Research Publishing Inc.

This work is licensed under the Creative Commons Attribution International License (CC BY). http://creativecommons.org/licenses/by/4.0/

(c) (i) Open Access

\section{Abstract}

The fact of providing the adequate attention to the educational needs of students in the school context is a challenge that requires both from teachers and parents the development of a set of competencies to let them maximize their capacities both individually and socially. Objective: To design an instrument to evaluate the teachers' degree of knowledge regarding the treatment of diversity in secondary school centers and the effectiveness of the education response obtained from them. Sample: 101 teachers from five educational centers in the northern region of the island of Tenerife. Instrument: The questionnaire "Questionnaire on attitudes towards the attention to diversity and orientation processes in Obligatory Secondary Education (CADESO)". Conclusion: The internal consistency of the proposed instrument, in general terms, has been proved to be satisfactory. It can be stated that this questionnaire appears to be a useful and reliable instrument to measure the objectives proposed in the study.

\section{Keywords}

Diversity, Secondary Education, Attention to Diversity, Specific Educational Support Needs (SESN) 


\section{Introduction}

Orientation processes and response to diversity are closely related, not only in the professional practice but also through the theoretical models on which their working models and their educational intervention are based.

The attention to diversity tries to eliminate the barriers as regards learning through the application of different measures in the school center and the classroom. It includes individual differences, related to motivation, interests, capacities, social origin, culture, gender, etc. and makes reference to a set of general and specific measures in the school centers, which vary depending on the needs of each student (Ferrandis, Grau, \& Fortes, 2010).

This concept is closely related to the concepts of inclusion, specific educational support needs (SESN) and special educational needs (SEN).

This diverse and heterogeneous reality demands collaboration and joint working from the education community. It also demands a close relationship between teachers and the Department of Educational Guidance.

Authors such as Pérez-Jorge (2010), Arnaiz (2012) and Escribano \& Martínez (2013) offer us a significant reflection, which summarizes the aim to achieve as regards the attention to diversity, related to the objective of the Curriculum Vitae. These authors consider that the CV has to be open and receptive to the students' diversity and has to offer them what they need taking into account their capacities, culture and gender. Moreover, the curriculum has to include in all its items the sensitivity to differences reflected in the school center. In this sense, the response to diversity can be present in everyday practices related to the teaching-learning process.

Educational guidance counselors and their department (Department of Educational Guidance) play an important role in this field. Although it seems to be simple, the diagnosis and adequateness of the educational response for students is a difficult task for both the educational guidance counselor and any other professional. This situation becomes more complex if we take into account that most of the teachers have not acquired these capacities or skills and have experienced significant changes related to the different regulations. This fact has made them adapt these changes to their classes, their students and their daily practice. They do not have new students but new ways to treat students. In this sense, it would be absurd to tell a teacher that his students have educational needs when he observes them every day. Moreover, it is necessary to make a distinction to respond to the students' needs. It is not a matter of searching for a label but finding a more reliable and adequate tool to respond to the needs of each student.

Secondary school teachers do not have the experience that primary school teachers have and they do not have the necessary academic and professional background that educational integration demands (Ferrandis, Grau, \& Fortes, 2010; Pereda, De Prada, \& Actis, 2012). Therefore, a skilled professional is required to collaborate with teachers with the aim of performing this task successfully. Consequently, this task is finally carried out by the Department of Educational Guidance.

Thus, it is of crucial importance to know the teachers' perspective as regards their daily activities with students because they are the ones who spend most of the time with their students, who ask for help from their educational guidance counselors. These counselors also assist families.

\section{Systematization and Approach to the Problem}

An adequate attention to diversity implies the elimination of barriers to learning through the application of different measures in the educational center and in the classroom. It also implies the necessity of knowing those differences related to motivation, interests, capacities, social origin, culture, gender, etc. and makes reference to a set of general and specific measures which the different educational centers have to include in their educational plan or project and also in their project of attention to diversity (Ferrandis, Grau, \& Fortes, 2010; Pérez-Jorge \& Rodríguez, 2011).

Therefore, in this study we attempt to evaluate the degree of knowledge and the expectations related to the attention to diversity and to the orientation processes from the perspective of obligatory secondary education teachers.

In summary, the problem of investigation can be synthesized through the following questions:

- What level of knowledge as regards education regulations and their application related to the attention to diversity do teachers have?

- What is the teachers' opinion about the effectiveness of the measures related to the attention to diversity in the classroom?

- What is the teachers' competence level to address the needs of students with SESN? 
- What is the teachers' perception as regards the Department of Educational Guidance?

The main objective of this study was to design an instrument to assess the teachers' degree of knowledge related to the approach to diversity in secondary educational centers and the effectiveness of their education response.

\section{Method}

In order to perform an empirical validation of the questionnaire during the academic course 2013-2014, we administered an on-line questionnaire (Berends, 2006), making use of Lime Survey platform, which was only applied to the sample of teachers. This strategy was used because it let us administer the questionnaire simultaneously to all the participants and offered us the possibility to export automatically the data obtained to SPSS, which was used to perform the analysis of the data.

\subsection{Sample Characteristics}

This research was performed in five educational centers in the northern region of the island of Tenerife with a sample of 101 teachers who participated voluntarily. The selection of the centers was carried out through a purposive non-randomized sampling procedure. The educational centers were chosen arbitrarily from the group of centers offered and linked through a collaboration agreement to the University of La Laguna in the academic course 2013-2014.

All the educational centers which participated in this study had a large number of professionals who taught in Obligatory Secondary Education, Upper Secondary Education and Professional Training. The sample was made up of 101 teachers, 36 males (35.6\%) and 65 females (64.4\%), aged 36 to 59, although most of them are over 50 years old $(58.4 \% . \mathrm{N}=59)$ compared to $41.6 \%(\mathrm{~N}=42)$ in the case of teachers under that age.

\subsection{Instruments}

This analysis was carried out taking into account a questionnaire created by Ferrandis, Grau \& Fortes (2010). This questionnaire was prepared and adapted according to the current regulations in the Autonomous Community in the Canary Islands as regards the attention to diversity and the processes of educational guidance and educational psychology. In particular, the adequateness of the questionnaire was performed according to the regulation Decree 104/2010, July 29, Decree 23/1995, February 24 and Order of September 1, 2010.

Different procedures were performed before the application of the final version of the questionnaire to adapt and validate its coverage and content: A pilot test was carried out with three obligatory secondary education teachers who had to evaluate different aspects related to the time devoted to the process of questionnaire administration, the reading and comprehension of the items. Furthermore, acontent test was also performed. Two teachers who were experts in disability and attention to diversity and two educational guidance counselors cooperated in this test. They assessed the adequateness, clarity and accuracy of the questions included in the questionnaire.

The questionnaire "Questionnaire on attitudes towards the attention to diversity and orientation processes in Obligatory Secondary Education (CADESO)” was finally made up of 60 items using Lickert Scale. Each item was valued punctuating from 1 (the lowest level of agreement) to 4 (the maximum level of agreement).

\section{Results}

Taking into account the objective of this study, an analysis of both the reliability and the underlying structure of CADESO was performed.

\subsection{CADESO Reliability Analysis}

In order to perform the reliability analysis, Cronbach's Alpha internal consistency coefficient has been used since we consider that our scale was made up of homogeneous elements which measured the same characteristic and its internal consistency could be evaluated through the average correlation among the different elements. The procedure was applied to 60 items in the teachers' questionnaire and a value of .80 was obtained, indicating a high consistency of the scale. 


\subsection{Analysis of the Underlying Dimensions of CADESO}

Taking into account CADESO metric properties, an analysis of the main components was performed to determine the underlying structure of the questionnaire. The analysis was carried out with the aim of interpreting the underlying relations as regards the correlation matrix and their decrease to understand the sense of the answers obtained better and improve this instrument for future applications. Furthermore, a VARIMAX rotation was used to produce an orthogonal structure of the results obtained, since the purpose to be attained is to get a structure which maximizes the independence among dimensions.

The index KMO and Bartlett test of sphericity are indicators of the magnitude of the linear relation among variables. The value of the index KMO of sampling adequateness obtained an acceptable value of .867 and enabled us to proceed with factorization. On the other hand, Bartlett test of sphericity proved to be significant $\left(\chi^{2}=(235\right.$, $\mathrm{N}=102)=12476.79 p<.000)$. Therefore, we determined the factor analysis based on correlation matrix. After some tests, we decided to opt for 7 components which explained a $60.384 \%$ of the variance. The composition of each factor (structure coefficient), the variance percentage which each factor explained, and their own values are shown in Tables 1-7.

Component 1 covers aspects related to the expectations and possibilities that teachers give their students with educational needs. In this sense, we try to observe the way in which the response to diversity (inclusion process of students with SESN) can affect the other students' performance.

Component 2 makes reference to the modification of the teaching practice with the aim of adapting it to the measures of attention to diversity in the classroom.

Component 3 it covers the teachers' perception as regards their professional qualification to detect and work with students with SESN.

Component 4 includes those items which have to do with the teachers' degree of knowledge about the regulations related to the attention of diversity and their application to students' daily practice.

Component 5 includes those items related to the organization of the educational center to deal with diversity in all its functions, (educational plan of the center, election of optional subjects, curricular adaptations, etc.)

Component 6 deals with the teachers' perception of the different processes of educational guidance related to

\section{Table 1. Student performance (items of CADESO questionnaire included in factor 1).}

Item (number)
To have students with difficulties in the classroom makes me forget those most capable students (37)
Students with SESN should be in other school centers (51)
students with learning difficulties are acquired in previous educational stages and I feel I am not able to help students
with SESN (45)
with SESN (45)

There are many students who “do nothing” and "let others do nothing”. It is better for them to be working (48)

The attention to diversity is not necessary. We only need students with academic enthusiasm. (47) with their classmates (57)

The attention to diversity is more effective in primary education because teachers are better qualified (49) 
Table 2. Application of measures in the classroom (items of CADESO questionnaire included in factor 2).

\begin{tabular}{lc}
\hline Item (number) & Value \\
\hline I carry out an individual assessment taking into account the type of students in the classroom (41) & .814 \\
I design my classroom activities programming according to the different paces of students learning (29) & .797 \\
My classes are dynamic and interactive for all my students (43) & .619 \\
I prepare different activities taking into account the characteristics of students (38) & .563 \\
I have to take into account the diversity of students in order to evaluate them (17) & .409 \\
My teaching materials are appropriate to the students' needs (32) & .391 \\
It is difficult to respond to diversity when there are 25 or 30 students per class (19) & .387 \\
I make use of cooperative work among students as a learning method (39) & .342 \\
\hline
\end{tabular}

Intrinsic value $=6.694 ; \%$ rotation variance $=9.881$.

Table 3. Teacher training (items of CADESO questionnaire included in factor 3).

\begin{tabular}{lc}
\hline Item (number) & Value \\
\hline I know how to detect and evaluate the students' specific educational needs (35) & .692 \\
I attend training courses when I have students with SESN (59) & .515 \\
I think I am adequately trained with the professional experience I have (15) & .430 \\
When I have a student with educational needs in my classroom I know how to work with him (34) & .429 \\
I am worried about the way to deal with students with SESN (50) & .314 \\
I think that the Education Administration does not train teachers adequately to address the demands of students & .308 \\
with SESN (60) & .301 \\
\hline
\end{tabular}

Intrinsic value $=5.437 ; \%$ rotation variance $=9.964$.

Table 4. Knowledge and application of education regulations (factor 4).

\begin{tabular}{l}
\hline Item (number) \\
The Decree 104/2010 has changed my didactic programming (7) \\
I know the Order June 7, 2007 related to the attention to diversity (3) \\
I know the Decree 104/2010 related to the attention to diversity (9) \\
I respond better to diversity with the Decree 104/2010 (11) \\
I follow the regulations related to the attention to diversity (1) \\
The measures of attention to diversity applied in my educational center are sufficient (5)
\end{tabular}

Intrinsic value $=4.617 ; \%$ rotation variance $=8.587$.

Table 5. Education center organization (items of CADESO questionnaire included in factor 5).

Item (number) Value

Curricular adaptations are purely bureaucratic processes. They are useless (21) .575

Educational support is organized to respond to students’ needs (26)

The attention to diversity has been considered when the Educational Plan of the Center has been developed (27)

Optional subjects available respond to students’ educational needs (23)

Measures of attention to diversity have been taken into account when the Tutorial Action Plan has been developed (28) .468

When a student repeats a school year I apply complementary educational measures (30) 465

An increase of the education budget would be necessary to allow the functioning of the attention to diversity (44)

The resources to address the attention to diversity could be applied to improve the overall quality of education (52) 397

Adaptations are not good because SEN students do not do the same things as the other students. They feel discriminated (56)

The optional subjects chosen by the student contribute to the attention to diversity (25) 320

Intrinsic value $=3.791 ; \%$ rotation variance $=7.326$. 
Table 6. Perception of orientation-educational guidance (items of CADESO questionnaire included in factor 6).

\begin{tabular}{|c|c|}
\hline Item (number) & Value \\
\hline Teachers need more help from educational guidance counselors to address those students with SESN (16) & .640 \\
\hline Educational guidance counselors provide adequate assistance in the development of private tutoring (22) & .559 \\
\hline The Department of Educational Guidance is only useful "to fill in forms” and does not offer any help in daily practice (6) & .540 \\
\hline The meetings held by the Department of Educational Guidance are a waste of time (20) & .538 \\
\hline $\begin{array}{l}\text { The Department of Educational Guidance offers teachers different materials and resources to address those students } \\
\text { with SESN (12) }\end{array}$ & .507 \\
\hline Educational guidance services adapt to the real needs of the educational center, students and teachers (24) & .479 \\
\hline The education center management is involved in the attention to diversity (33) & .468 \\
\hline The educational guidance counselor should devote more time to teachers (18) & .432 \\
\hline I receive attention from educational guidance counselors (10) & .397 \\
\hline I think that the Department of Educational Guidance is necessary (14) & .396 \\
\hline When I have a problem or a difficulty I request the help of the educational guidance counselor (8) & .394 \\
\hline There is an adequate coordination between teachers and the Department of Educational Guidance (2) & .383 \\
\hline The Department of Educational Guidance collaborates with teachers as regards the attention to diversity (4) & .361 \\
\hline
\end{tabular}

Intrinsic value $=3.244 ; \%$ rotation variance $=7.274$.

Table 7. Social relationships (Items of CADESO questionnaire included in factor 7).

Item (number)
The fact of having students with SESN enriches my classes (42)
I do not want to have students with SESN in my classroom because I have not been asked if I want to have them (53)

Intrinsic value $=3.042 ; \%$ rotation variance $=7.033$.

the perception of coordination, help, need or relevance of the Department of Educational Guidance to address the diversity of students.

Component 7 is composed of items related to the teachers' attitude before students with SNES.

As a conclusion, it can be summarized that, after the analysis of the different items of CADESO, the following 7 major factors have been obtained:

1) Factor 1: Student performance

2) Factor 2: Application of measures in the classroom

3) Factor 3: Teacher Training

4) Factor 4: Knowledge and Application of Education Regulations

5) Factor 5: Education Center Organization

6) Factor 6: Perception of Orientation (Educational Guidance)

7) Factor 7: Social Relationships.

\section{Conclusions}

The main objective of this research has been to design an instrument to assess the degree of knowledge regarding the treatment of diversity in obligatory secondary school centers and the effectiveness of the education response obtained from them. To analyze how secondary education teachers perceive the way to respond to diversity has let us observe the degree of knowledge and the procedures to be followed to give students with SNES an adequate educational response. We consider that the design of an adequate instrument to analyze these dimensions is very important in order to detect the teachers' educational and qualification requirements in the field of the response to diversity.

The internal consistency of the instrument designed has been proved to be satisfactory. The 7 subscales obtained have shown reliability values of .80. From the 60 items included in this questionnaire and after perform- 
ing several tests, we have observed that the reliability could be modified with the deletion of each item. This analysis recommends us eliminate or modify in future studies the items 32, 50, 52 and 60.

It can be stated that, after studying CADESO metric properties, this instrument is both reliable and adequate. Therefore, it can be recommended as a tool to examine the processes of attention to diversity and the response to SESN. Thus, the validity of the evidence and its internal structure appear to be adequate as regards its content (validated by experts). In this sense, the factors obtained have been proved to be coherent with the theoretical dimensions proposed by Ferrandis, Grau \& Fortes (2010).

The data reduction procedure (factorization) used has also proved to be adequate and coherent as regards the dimensions given. Therefore, we propose, in future analyses and as regards the interpretation of results, to consider these dimensions due to their theoretical value and consistency.

\section{References}

Arnaiz, P. (2012). Escuelas eficaces e inclusivas: Cómo favorecer su desarrollo. Education Siglo XXI, 30, 25-44.

Berends, M. (2006). Survey Methods in Educational Research. In J. L. Green, G. Camilla, \& P. B. Elmore (Eds.), Handbook of Complementary Methods in Education Research. Washington: AERA.

Escribano, A., \& Martínez, A. (2013). Inclusión educativa y profesorado inclusivo. Aprender juntos para aprender a vivir juntos. Madrid: Narcea.

Ferrandis, M. V., Grau, C., \& Fortes, M. C. (2010). El profesorado y la atención a la diversidad en la ESO. Educación inclusiva, 3, 11-28.

Pereda, C., De Prada, M., \& Actis, W. (2012). Discapacidad e inclusión social. Barcelona: Obra Social La Caixa.

Pérez-Jorge, D. (2010). Actitudes y concepto de la diversidad humana: Un estudio comparativo en centros educativos de la isla de Tenerife. Tenerife. Universidad de La Laguna.

Pérez-Jorge, D., \& Rodríguez, M. (2011). Actitudes de los maestros hacia las necesidades especiales de los alumnos. In O. M. Alegre (2012) Investigación sobre competencias y tecnología para la inclusión y la interculturalidad. Madrid: Arial (12), 180-196. 